\title{
POLARIZED IR REFLECTANCE SPECTROSCOPY METHODS FOR THE ORIENTATION OF MONOCLINIC SINGLE CRYSTALS: TUTTON SALTS AS A CASE EXAMPLE
}

\author{
Vladimir Ivanovski \\ Institute of Chemistry, Faculty of Natural Sciences and Mathematics, Ss. Cyril and Methodius University, \\ Arhimedova 5, 1000 Skopje, Republic of Macedonia \\ vladimir@pmf.ukim.mk,vladimir.ivanovski@yahoo.com
}

\begin{abstract}
Investigation of polarized IR reflectance spectra of single crystals is important in the course of obtaining vibrational, optical and dielectric properties of solid state samples. Diffraction X-ray methods are usually employed for crystal orientation. In this work, two IR reflectance methods were proposed as a supplement in determining the orientation of the $b$ crystal axis and by that the $a c$ crystal plane, in respect to the morphology of monoclinic single crystals. The methods were tested on two Tutton salt single crystals $\left(\mathrm{K}_{2} \mathrm{Ni}\left(\mathrm{SO}_{4}\right)_{2} \cdot 6 \mathrm{H}_{2} \mathrm{O}\right.$ and $\left.\mathrm{K}_{2} \mathrm{Ni}\left(\mathrm{SeO}_{4}\right)_{2} \cdot 6 \mathrm{H}_{2} \mathrm{O}\right)$ which were further compared with the cross-polarization IR reflectance method. Both methods relied on the symmetry and optical properties of monoclinic single crystals. One takes into account the fact that one of the principal axes of the dielectric tensor was symmetry fixed, while the other used the conditions for the appearance of an isosbestic-like point/region in the polarized IR reflectance spectra of single crystals with low symmetry.
\end{abstract}

Keywords: polarized IR reflectance; Tutton salts; orienting single crystal; isosbestic point; monoclinic crystals

\section{МЕТОДИ ЗА ОРИЕНТАЦИЈА НА МОНОКЛИНИЧНИ МОНОКРИСТАЛИ БАЗИРАНИ НА ПОЛАРИЗИРАНА ИФРАЦРВЕНА РЕФЛЕКСИОНА СПЕКТРОСКОПИЈА: ТУТОНОВИ СОЛИ КАКО ПРИМЕР}

\begin{abstract}
Истражувањето на поларизираните инфрацрвени рефлексиони спектри на монокристални примероци е важно во насока на добивање вибрациони, оптички и диелектрични својства на кристалните примероци. Методите со користење рендгенско зрачење се најчесто употребувани во ориентација на монокристали. Во овој труд се предложени два додатни инфрацрвени рефлексиони метода за проверка и определување на ориентацијата на кристалната оска $b$ и со тоа на кристалната рамнина $a c$, во однос на морфологијата на монокристалот. Методите се проверени врз два монокристала од Тутонови соли: $\mathrm{K}_{2} \mathrm{Ni}\left(\mathrm{SO}_{4}\right)_{2} \cdot 6 \mathrm{H}_{2} \mathrm{O}$ и $\mathrm{K}_{2} \mathrm{Ni}\left(\mathrm{SeO}_{4}\right)_{2} \cdot 6 \mathrm{H}_{2} \mathrm{O}$ и исто така се споредени со инфрацрвениот метод на вкрстена поларизација. Двата метода се базираат на симетријата и оптичките особини на моноклиничните монокристали. Едниот од нив го зема предвид фактот дека една од главните диелектрични оски е симетриски фиксирана, додека другата го користи условот за појава на изобестички слична точка, односно изобестички слична област во поларизираните инфрацрвени рефлексиони спектри на монокристали со ниска симетрија.
\end{abstract}

Клучни зборови: поларизирана инфрацрвена рефлексија; Тутонови соли; ориентирање на монокристали; изобестичка точка; моноклинични кристали 


\section{INTRODUCTION}

Many properties can be obtained from the polarized IR investigation of single crystals with symmetry lower than cubic. A complete data on the vibrational, optical and dielectric crystal properties can be acquired this way [1-9]. Even in order to model (simulate) optical and dielectric properties of a polycrystalline sample, according to the newly developed theories [10-12], the knowledge of the dielectric tensor of a single crystal in the studied frequency range is needed, in particular, when the crystal is of monoclinic symmetry. Before spectra are recorded for further analysis, the orientation of the single crystal is required, i.e. finding the directions of the crystal axes with respect to crystal morphology. This is usually accomplished by X-ray diffraction experiment. It is sometimes coupled with an optical goniometer, in cases when the optical axis needs to be determined $[13,14]$. Even then, a skill is needed in order to orient samples of single crystals with relatively large crystal surfaces $(\sim 0.5 \times 0.5 \mathrm{~cm}$ at minimum $)$ which are favorable for IR reflectance measurements. X-ray goniometers, offered nowadays at the instrument market are routinely employed in the orientation of large single crystals [15]. Nevertheless, such kind of equipment rarely accompanies laboratories investigating vibrational properties of materials. Thus, the possibility to employ the existing IR spectrometer for checking on the orientation of single crystals, for which the morphology and the structure has been reported, makes the process of investigation easier.

The methods proposed in this study relied on the symmetry selection rules and the laws of crystal optics. The selection rules for monoclinic crystal system are such that they allow discrimination of the vibrations from different symmetries by using polarized light [9]. By having the polarization vector of the external electric field along the $b$ crystallographic axis or in the $a c$ crystal plane, it is possible to distinguish between vibrations of $A$ and $B$ ( $C_{2}$ factor group), $A^{\prime}$ and $A^{\prime \prime}$ ( $C_{\mathrm{s}}$ factor group) or $A_{\mathrm{u}}$ and $B_{\mathrm{u}}\left(C_{2 \mathrm{~h}}\right.$ factor group) symmetry type [16]. There is one principal difference between vibrations of different symmetry types. Namely, if the $b$, i.e. $y$ axis is chosen as unique axis, the $A, A^{\prime}$ and $A_{\mathrm{u}}$ symmetry type vibrations have transition dipole moments oriented along (i.e. parallel to) this axis which is, in the same time, a principal dielectric axis [17], while $B, A^{\prime \prime}$ and $B_{\mathrm{u}}$ vibrations have transition dipole moments lying in the $a c$ crystal plane [16]. For the later vibrations it is commonly said that they are frequency dependent $[17,18]$, i.e. the orientation of their transition dipole moment in the $a c$ plane depends on the frequency of the oscillator. Fortunately, theories exist for the model dielectric function that can be used to determine the dielectric, optical and vibrational properties of monoclinic single crystals under the condition of reflection at near-normal $[18,19]$ or oblique incidence angle [20].

Cross-polarization IR spectroscopy methods are currently used to check the orientation of single crystals [21, 22]. Thus, a comparison in the sense of pros and cons of here proposed methods to cross-polarization is elaborated, too. To test crystal orientation using here proposed methods, FTIR spectrometer, equipped with a polarizer and reflectance cell at near-normal incidence is needed. Using these methods, the orientation of the $b$ axis in monoclinic crystals can be checked or even found. However, to identify the $b$ crystal axis direction on a new crystal sample requires trial and error measurements from crystal faces. The number of trials can be reduced by using a guide in morphological data, as for example the one presented in [23]. Knowing the direction of the $b$ axis with respect to the crystal morphology is sufficient for some IR investigations, such as investigating modes of different symmetry type. However, for a proper identification of the $a$ and $c$ crystal axes directions in a single crystal, other techniques (like single crystal $\mathrm{X}$-ray diffraction) are indispensable.

In this work, two methods for the orientation of monoclinic single crystals were proposed based on specular reflectance IR spectroscopy and were applied to two different Tutton salts, $\mathrm{K}_{2} \mathrm{Ni}\left(\mathrm{SeO}_{4}\right)_{2} \cdot 6 \mathrm{H}_{2} \mathrm{O}$ and $\mathrm{K}_{2} \mathrm{Ni}\left(\mathrm{SO}_{4}\right)_{2} \cdot 6 \mathrm{H}_{2} \mathrm{O}$ (hereafter $\mathrm{KNiSeH}$ and $\mathrm{KNiSH}$ ). These crystals were used as model materials since a lot of our work has been dedicated to the investigation of molecular properties of Tutton salt single crystals using polarized IR reflectance measurements [1-4, 24]. Particular attention was paid to the $\mathrm{v}_{3}\left(\mathrm{SeO}_{4}{ }^{2-}\right)$ and $\mathrm{v}_{3}\left(\mathrm{SO}_{4}{ }^{2-}\right)$ frequency regions, since the most prominent bands (as well as the most prominent differences) in the spectra of the two salts were located there.

Basic orientation of the single crystals was performed using an optical goniometer [2] and published morphological data [23]. The first method was based on the equal appearance of the polarized IR reflectance spectra obtained from crystal planes parallel to the $b$ crystal axis. The second method relied on the characteristic appearance of an isosbestic-like point or isosbestic-like region (ILP or ILR, respectively) [25, 26]. These terms should not be confused with the isosbestic-point defined by IUPAC being the "wavelength, wave- 
number or frequency at which the total absorbance of a sample does not change during a chemical reaction or a physical change of the sample" and primarily used in the UV-Vis investigations [2729]. According to IUPAC [30], an example of the appearance of an isosbestic point is:

"... when one molecular entity is converted into another that has the same molar absorption coefficient at a given wavelength. As long as the sum of the concentrations of the two molecular entities in the solution is held constant there will be no change in absorbance at this wavelength as the ratio of the concentrations of the two entities is varied".

The appearance of the ILP as explained in Section 4 (eq. 1), might be defined as: frequency, wavelength or wavenumber at which the reflectance of two partially-overlapping reflectance bands originating from two modes with mutually perpendicular transition dipole moments are independent of the angle of polarization in the plane formed by the transition dipole moments. The analogy between the isosbestic point and the isosbestic-like point is the existence of a non-variable spectral property (absorbance and reflectance, respectively) when changing the conditions (chemical/physical change and polarization change, respectively). Previous works on the reflectance spectra of crystals reveals that in crystal systems with symmetry higher then monoclinic, the appearance of an ILP is connected to the alignment of the vibrating dipoles along the principal dielectric axes [26].

As a comparative method for a crystal orientation, cross-polarization IR reflectance spectra of the investigated crystals were given and discussed.

The primary aim of this paper was not to propose methods that could substitute for diffraction methods of crystal orientation, rather describe methods that could be used to check crystal orientation and determine the orientation of the $b$ crystal axis and the $a c$ crystal plane. This paper also showed how, by using simple arguments from the theory of light propagation in crystal solids, the theory of crystal symmetry and the theory of the dielectric properties of crystals with low symmetry, could lead to experimental possibilities for crystal orientation.

\section{EXPERIMENTAL}

A single crystal of $\mathrm{KNiSeH}(1 \times 1 \times 0.5 \mathrm{~cm})$ was grown by slow evaporation from an aqueous solution that contained sublimated $\mathrm{SeO}_{2}$ powder dissolved in water to which $32 \% v / v \mathrm{H}_{2} \mathrm{O}_{2}$ was added. This solution (containing $\mathrm{H}_{2} \mathrm{SeO}_{4}$ acid) was added to an aqueous suspension of $\mathrm{NiCO}_{3} \cdot \mathrm{Ni}(\mathrm{OH})_{2}$, and to an aqueous solution of $\mathrm{K}_{2} \mathrm{CO}_{3}$. The solutions of $\mathrm{NiSeO}_{4}$ and $\mathrm{K}_{2} \mathrm{SeO}_{4}$ were finally mixed.

A single crystal of $\mathrm{KNiSH}$ with size $0.7 \times$ $0.7 \times 1.5 \mathrm{~cm}$ was obtained by a slow evaporation of an equimolar aqueous solution of $\mathrm{K}_{2} \mathrm{SO}_{4}$ and $\mathrm{NiSO}_{4} \cdot 7 \mathrm{H}_{2} \mathrm{O}$. In both cases, the seeds (after their appearance) were transferred into flat-bottomed glass vessels with and the corresponding solution was added. Roughly two months were needed for the crystals to grow.

Both crystals were monoclinic, space group $P 2{ }_{1} / a$, with $Z=2$ and unit cell parameters of : $a=$ $898.5 \mathrm{pm}, b=1216.7 \mathrm{pm}, c=612.8 \mathrm{pm} ; \beta=105.08^{\circ}$ for KNiSH [31], and $a=917.9 \mathrm{pm}, b=1236.7 \mathrm{pm}$, $c=625.4 \mathrm{pm}$ and $\beta=104.46^{\circ}$ for KNiSeH [32]. The unit-cell group for both crystals was $C_{2 \mathrm{~h}}$. Crystal faces $a c, b c$ and $a b$ parallel and perpendicular to the $b$ crystallographic axis were cut and polished.

IR polarized reflectance was performed using Varian Excalibur 3000 FT-IR spectrometer with $16^{\circ}$ or $5^{\circ}$ near-normal incidence angle while cross-polarization measurements were performed on a Perkin-Elmer System 2000. Polarization of the IR beam was obtained using an external KRS5/Al polarizer positioned for $s$-polarization. For cross-polarization measurements, the analyzer was positioned either parallel to the polarizer (sspolarization) or perpendicular to the polarizer ( $s p$ polarization). In order to obtain reflectance spectra which were supported by the theory used in this study, incidence angle closer to zero were needed. However, recording polarized reflectance spectra during a stepwise rotation of the sample around a fixed crystal axis could be performed only with the available Perkin-Elmer fixed angle reflectance accessory. Although the incidence angle was $16^{\circ}$ it did not alter the results and the final conclusions. Using this accessory, polarized reflectance spectra were recorded from the $a c, b c$ and $a b$ crystal face using $4 \mathrm{~cm}^{-1}$ resolution for every $20^{\circ}$ of polarization angle, ranging from $0^{\circ}$ to $180^{\circ}$. Also, spectra at a near-normal incidence angle of $5^{\circ}$ were recorded with polarization along the crystal axes using a Seagull (Harrick) variable-angle reflection accessory. Spectra from other crystal planes (that were not present by the morphology of the crystal samples) were obtained on the same crystals. Corresponding planes were obtained using cutting and polishing of the crystal.

The procedure for crystal orientation was as follows: grown single crystals were compared with morphological data (in this case ref. [23]) and crystal planes and directions identified on the crystal sample. If the necessary planes existed in the crystal, the IR reflectance recordings could be obtained from the plane, or after its polishing (to exclude 
possible roughness or make the reflectance plane larger). If the plane was not present in the crystal (e.g. (010) plane in Tutton salts), cutting and polishing was required before recording spectra. As these were soft crystals "cutting" was actually polishing where rough polishing was performed using sand-paper of different grits and fine polishing was performed using $1 \mu \mathrm{m}$ diamond suspension and a liquid lubricant/coolant. After the plane was polished to optical quality, IR reflection spectra were recorded in accordance with the proposed methods. If the obtained results did not match those expected, another set of planes was checked, until satisfactory results were obtained.

\section{THEORETICAL BACKGROUND}

The orientation of the monoclinic single crystal was based on the following principles of crystal optics:
1. Consider a plane wave with a wave vector $\vec{k}$ in the direction of one of the crystal's principal dielectric axes (e.g. y) and linear polarization along the other axes (e.g. $x$ ), falling perpendicularly on the crystal surface (Figure 1). The reflected and refracted waves will be then linearly polarized, retaining the polarization of the incoming ray $[33,34]$.

2. Consider a plane wave with a wave vector $\vec{k}$ in the direction of one of the crystal's principal dielectric axes (e.g. y) and a linear polarization at an azimuth angle between the other two principal axes (e.g. $x$ and $z$ ), falling perpendicularly on the crystal surface (cf. Figure 1). The reflected and refracted waves will then be elliptically polarized due to the retardation in the phases of the electric fields along the principal $x$ and $z$ axes (being frequency dependent in monoclinic crystals [33]).
1)

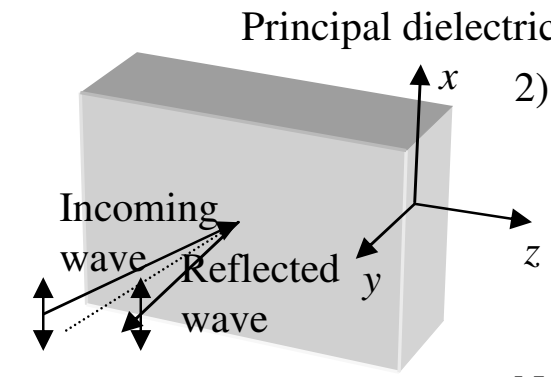

Normal to the

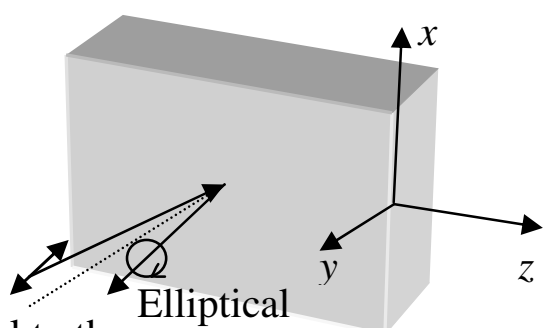

crystal plane
3)

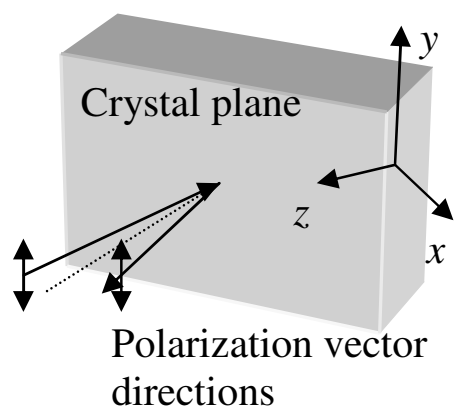

Fig. 1. Schematic representation of the cases: 1, 2 and 3.

In 1 - no change in reflected polarization (along one of the principal axis) occurs when the incoming wave impinges normally along one of the principal dielectric axes with polarization along the other; $\mathbf{2}$ - elliptical polarization in the reflected wave occurs when the incoming wave impinges normally on a crystal plane along one of the principal axes, but with linear polarization not along any of the principal axes; $\mathbf{3}$ - no change in polarization in reflection occurs if the incidence wave is perpendicular to the $y$ symmetry axis (monoclinic crystal system), with polarization along the axis.

2.1. In more general case, if the wave vector is along an arbitrary direction in the crystal, two linearly-polarized waves will result, with polarization vectors mutually perpendicular constituting the long and the short axis of the el- lipse obtained as an intersection between the ellipsoid of wave normals and the plane perpendicular to the wave vector [17]. If this arbitrary direction of the wave vector is perpendicular to the $y$ principal axis (i.e. $b$ crystal 
axis in monoclinic crystals), then one of the axis of the ellipsoid will be along the $y$ axis, while the other will be fixed and perpendicular to it. If the wave is initially polarized in the direction of $b$ axis, this polarization will remain on reflection or refraction.

3. Consider a plane wave with a wave vector $\vec{k}$ lying in the crystal's principal dielectric plane $x z$ (where principal dielectric axes directions for monoclinic crystals are frequency dependent [17]) and polarization vector along the $y$ principal dielectric axis. On reflection and refraction, this polarization will be preserved (Figure 1).

\section{RESULTS AND DISCUSSION}

One possibility for spectroscopic identification of the unique $b$ crystallographic axis was to record polarized spectra with the polarization of the incidence radiation along $b$ axis, and normal (actually near-normal) reflectance from different planes parallel to this direction [24]. This experimental setup is in accordance with the Section 3, point 3 , and one would expect identical spectra.
One must be however very careful if only the result of this rule was taken into account. If for example, polarized spectra were recorded from symmetry equivalent planes (110) and $(1 \overline{1} 0)$, with polarization along the $c$ crystal axis ( $c$-polarization in the following text) the result shown in Figure 2 were obtained.

These data showed the reflectance spectra recorded from the (110) and (1 $\overline{1} 0)$ planes were the same. This occurred because of the presence of the glide plane (effectively a mirror plane) perpendicular to the $b$ axis, so all the projections of the transition dipole moments whether of $A_{\mathrm{u}}$ symmetry type (along the $b$ axis) or $B_{\mathrm{u}}$ symmetry type (in the ac crystal plane), were the same for both (110) and $(1 \overline{1} 0)$ planes. Additionally, the projection of polarization directions onto the $b$ axis and the $a c$ plane of the two extraordinary rays (Section 3, point 2.1), would be the same. To confirm this, $s$ polarized near-normal reflectance spectra were recorded from these planes, rotating the $\mathrm{KNiSeH}$ crystal about the normal to each of the planes, counterclockwise for the (110) and clockwise for the $(1 \overline{1} 0)$ plane (Figure 3$)$.
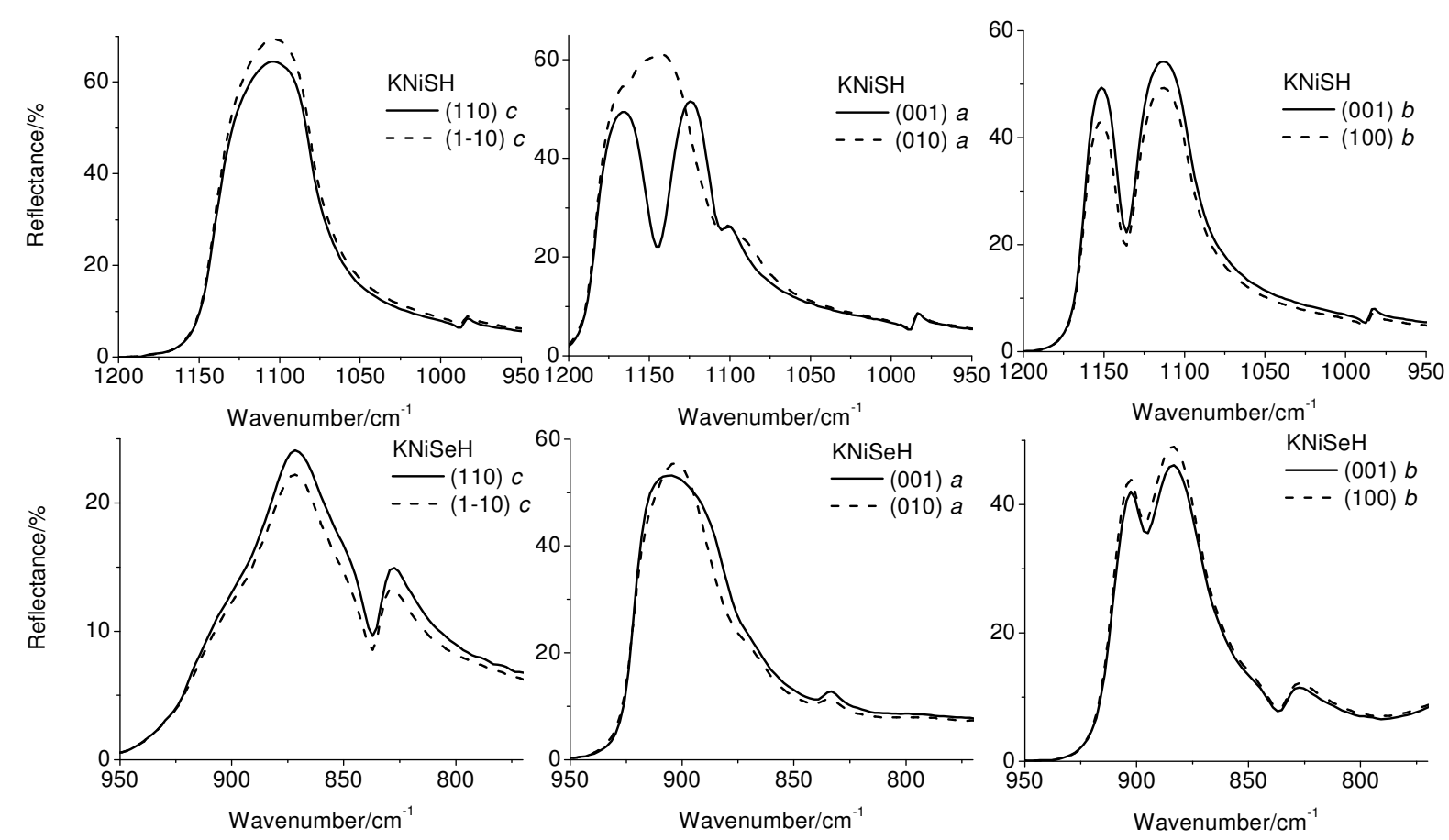

Fig. 2. $c$-Polarized spectra recorded from symmetry equivalent $(110)$ and $(1 \overline{1} 0)$ planes for KNiSH and KNiSeH (left); the spectra are identical except for the intensity. For $a$-polarized spectra recorded from symmetry non-equivalent $(001)$ and (010) planes (middle); the spectra are different. For $b$-polarized spectra recorded from symmetry non-equivalent (001) and (100) planes (right); the spectra are the same except for the intensity. 


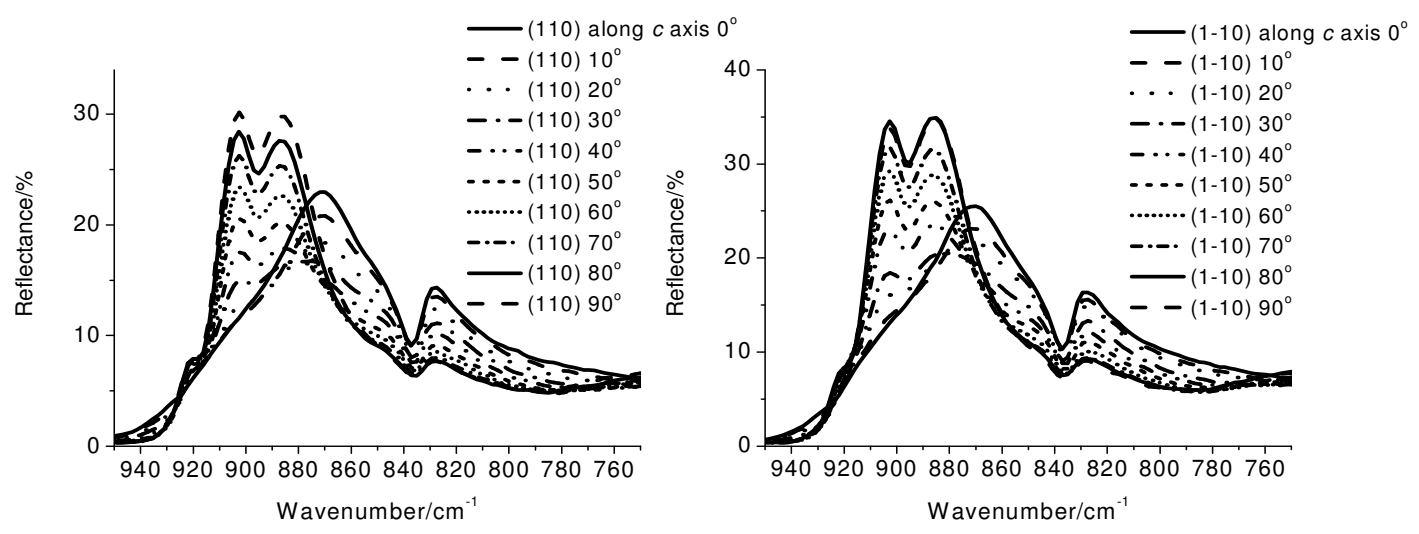

Fig. 3. Polarized reflectance spectra recorded from the (T10) and (110) planes in a KNiSeH single crystal.

The crystal was rotated about the normal to the planes counterclockwise and clockwise, respectively, with a step of $10^{\circ}$, starting with polarization along the $c$ direction. Spectra for each polarization angle recorded from different plane are the same.

Due to different polishing qualities of the crystal faces, the reflectance from the two planes differs slightly.

Figure 3 shows that the corresponding spectra recorded from these two different planes, but for the same angle of polarization, were practically identical. The angle of polarization was the one between the polarization direction in the corresponding plane and the $c$ axis.

The previous data suggested that if identical reflectance spectra were obtained for the same polarization direction by recording from symmetry equivalent planes, it did not necessarily mean that this polarization direction was parallel to a symmetry axis.

To check whether a certain direction was parallel to an axis of symmetry, spectra from nonequivalent crystal faces should be recorded. This was the case when spectra with polarization along the $a$ crystal axis from the (001) and (010) crystal plane were recorded and compared (cf. Figure 2 middle). The two planes cannot be mapped onto each other via a symmetry operation. Also, due to crystal anisotropy, the reflectance spectra recorded with polarization along the $a$ axis would be different. As seen from Figure 2, the spectra differed for $\mathrm{KNiSH}$ in the $\nu_{3}\left(\mathrm{SO}_{4}{ }^{2-}\right)$ region, in that, a singlet band was present for the spectrum recorded from the (001) plane while a doublet when the spectrum was recorded from the (010) plane. On the other hand, a complex band with comparable maximum reflectance frequencies appeared in the $v_{3}\left(\mathrm{SeO}_{4}{ }^{2-}\right)$ region for spectra recorded from the (001) and (010) planes in the KNiSeH single crystal. Nevertheless, the band profiles were different (cf. Figure 2 ). These data were opposite when $c$-polarized spectra from symmetry equivalent planes were recorded (cf. Figure 2).

Finally, spectra were recorded with polarization along the $b$ axis, from (001) and (100) crystal planes, which are symmetry non-equivalent (Fig- ure 2). Obviously, pairs of spectra were identical for both $\mathrm{KNiSH}$ and $\mathrm{KNiSeH}$ single crystals. This was due to the fact that although the $b$ crystal axis was an axis of symmetry, it also coincided with the direction of the $y$ principal axis of the dielectric tensor [17]. Thus, the theory in Section 3, point 2.1 was applicable; polarized IR reflectance spectra, recorded for the same incidence angle from planes parallel to the $b$ axis with polarization along this axis, would be the same.

For method one, if near-normal s-polarized reflectance spectra were recorded under the same direction of polarization, but from symmetry nonequivalent crystal faces, they would yield identical spectra, where the direction of polarization was parallel to the direction of the $b$-crystal axis and the perpendicular plane was the $a c$ crystal plane. The method should also apply to non-centrosymmetric monoclinic crystals belonging to sphenoidal and domatic crystal classes $\left(C_{2}\right.$ and $C_{\mathrm{s}}$ factor groups, respectively). Although the $C_{\mathrm{s}}$ factor group lacks a twofold symmetry axis, the $y$ principal axis of the dielectric tensor is still oriented along the unique axis, in this case, the $b$ axis.

The second method for orientation of monoclinic single crystals proposed in this work may be the most robust with respect to the experimental efforts needed, but could (as will be demonstrated) give more precise results. It was based on the theory of the appearance of an ILP in the polarized reflectance spectra of single crystals, particularly the appearance of an ILR in monoclinic crystals [26]. The basic concept was that an ILP would be present in the superimposed polarized IR reflectance spectra recorded from a principal plane if all transition dipole moments were oriented along the principal dielectric axes. This condition is satisfied 
however for crystals with symmetry as low as orthorhombic and is not (in principle) for spectra taken from the $a c$ crystal plane in monoclinic crystals. In certain special cases, an ILR (i.e. a close frequency region in which all reflectance bands intersect) can also appear in the reflectance IR spectra for vibrations with transition dipole moments in the $a c$ crystal plane $[25,26]$, indicating that transition dipole moments of the vibrational modes are almost perpendicular [1-3]. The closer to perpendicular the directions of the transition dipole moments were, and the closer to being oriented along the directions of the background dielectric tensor $\varepsilon(\infty)$ principal axes [26], the more ILR approached ILP. Our previous qualitative investigations on the appearance of the ILP in $\mathrm{KNiSH}$ and $\left(\mathrm{NH}_{4}\right)_{2} \mathrm{Ni}\left(\mathrm{SO}_{4}\right)_{2} \cdot 6 \mathrm{H}_{2} \mathrm{O}$ Tutton salts
[25], showed that such a point/region appears for spectra recorded from the ac crystal plane in the region of $\mathrm{SO}_{4}{ }^{2-}$ stretching vibrations. It was assumed, this was due to the perpendicular orientation of the transition dipole moments of the $B_{\mathrm{u}}$ symmetry type for $\mathrm{SO}_{4}{ }^{2-}$ stretching vibrations. This special orientation was thought to be valid for all Tutton salts, irrespective of their composition (i.e. the nature of the univalent and divalent cation and/or the anion). However, our recent investigations of the polarized reflectance spectra of $\mathrm{KNiSeH}$ and the performed dispersion analysis proved this (implicit) assumption is false [35]. Thus, no ILP (and not even an ILR) appeared when the polarized IR spectra were recorded from the $a c$ crystal plane in the frequency region of $\mathrm{SeO}_{4}{ }^{2-}$ stretching vibrations (Figure 4).

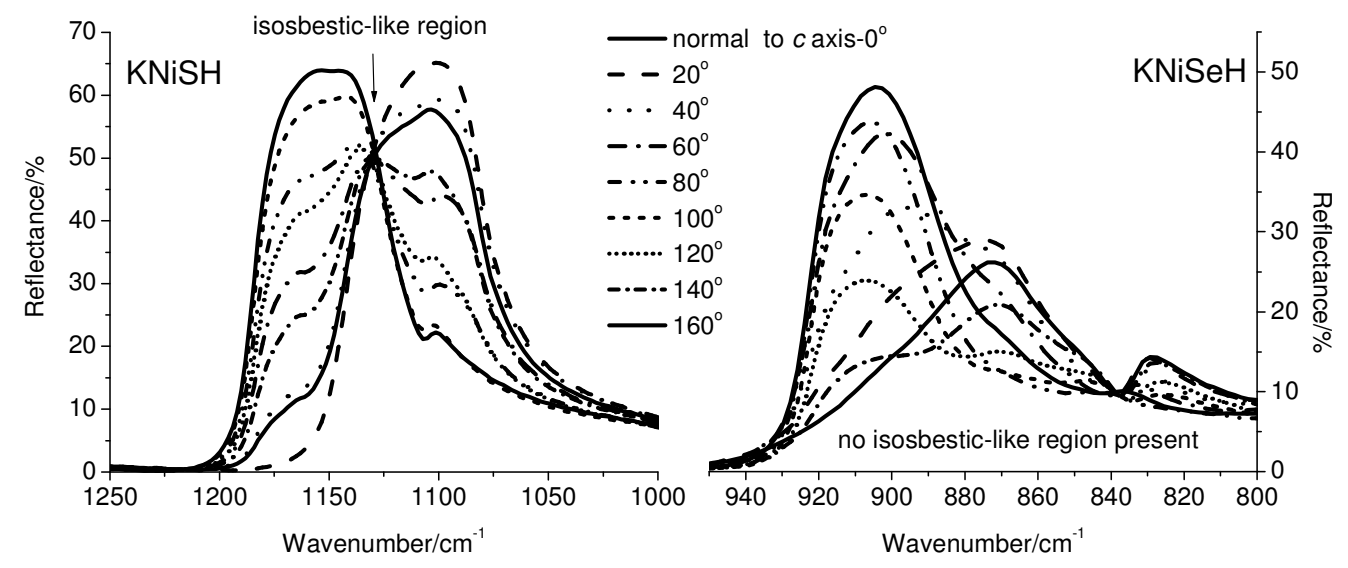

Fig. 4. Polarized reflectance spectra recorded from the $a c$, (010) crystal plane of $\mathrm{KNiSH}$ and $\mathrm{KNiSeH}$ single crystals in the $v_{3}\left(\mathrm{SO}_{4}{ }^{2-}\right)$ and $v_{3}\left(\mathrm{SeO}_{4}{ }^{2-}\right)$ frequency region. Polarized spectra were recorded starting perpendicular to the $c$ axis with a step of $20^{\circ}$ to $160^{\circ}$.

This picture however might lead to a wrong conclusion that crystal orientation was incorrect. This, as will be shown, was not the case.

The theoretical support for the experiment was given in Section 3, point 2.1, namely, when the wave vector of the incoming radiation was perpendicular to the $b$ axis, one extraordinary ray will have a polarization vector along the $b$ axis, while the second will be perpendicular to it. From the proposed theory on the appearance of the ILP [26], it follows that the ILP/ILR will appear if two mutually perpendicular in-plane directions existed in monoclinic crystals along which all transition dipoles are aligned. Strictly speaking, there are no such directions. However, all transition dipole moments of $B_{\mathrm{u}}$ symmetry type, although randomly oriented in the $a c$ plane, can be projected in any arbitrary direction in the $a c$ crystal plane, which is also perpendicular to the $b$ crystal axis. Thus, the plane formed for the direction that was in the $a c$ plane and the $b$ axis, should satisfy the condition for the appearance of an ILP i.e. ILR, in its polarized reflectance spectra. This condition would be naturally satisfied for $a b$ and $b c$ crystal planes, due to the perpendicularity between the $b$ axis and the $a$ and $c$ axes. Thus, an ILR (more common than ILP, as the angle of incidence departed from $0^{\circ}$ ) was expected to form in the polarized IR reflectance spectra of $a b(001)$ and $b c$ (100) planes of the monoclinic crystals (Figure 5).

In polarized spectra from the $a b$ and $b c$ planes, for $\mathrm{KNiSH}$ and $\mathrm{KNiSeH}$ the ILR was well established. Apart from the appearance of the ILR, the spectra for the pairs of supplement angles of polarization $\left(0^{\circ}, 180^{\circ}\right),\left(20^{\circ}, 160^{\circ}\right),\left(40^{\circ}, 140^{\circ}\right)$, $\left(60^{\circ}, 120^{\circ}\right)$ and $\left(80^{\circ}, 100^{\circ}\right)$ for the $a b$ plane in $\mathrm{KNiSH}$ were nearly identical. 

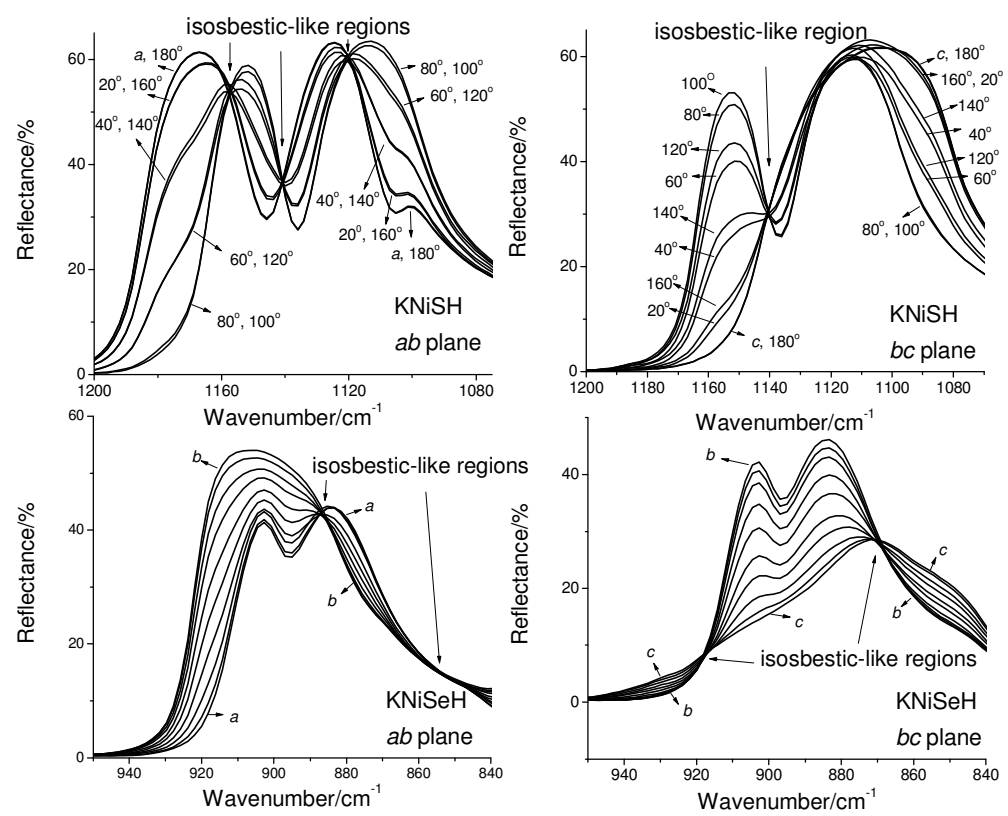

Fig. 5. Polarized reflectance spectra of KNiSH (upper two graphs) recorded from the $a b$, (001) (upper-left) and $b c,(100)$ (upper-right) crystal planes. Spectra are presented with a polarization angle ranging from $0^{\circ}$ to $180^{\circ}$ with a step of $20^{\circ}$. Polarized reflectance spectra of $\mathrm{KNiSeH}$ (lower two graphs) recorded from the $a b$, (001) (lower-left) and $b c,(100)$ (lower-right) crystal planes showing the ILRs. Spectra are presented with polarization angles ranging from $0^{\circ}$ to $90^{\circ}$ with a step of $10^{\circ}$. Angles of polarization within the reflecting plane are also indicated.

That the appearance of ILR was due to perpendicular nature of the directions can be checked using eq. (1) [25].

$$
R=R_{1} \cos ^{2} \phi+R_{2} \cos ^{2}\left(90^{\circ}-\phi\right) ; 0 \leq \phi \leq 90^{\circ}
$$

Generated spectra based on eq. (1) at $\phi$ angle of polarization are shown in Figure 6. $R_{1}$ and $R_{2}$ in the eq. (1) were the polarized reflectance spectra along the $b$ and $a$ axes recorded from (001), or the polarized reflectance spectra along $b$ and $c$ if recordings were performed from (100) plane.
The match of the recorded polarized spectra in Figure 5 with the corresponding calculated spectra in Figure 6 was undeniable. The reason for the appearance of ILP cannot be the existence of the two optical axes in biaxial crystals although it is true that if the direction of propagation coincides with the optical axis the crystal behaves as isotropic, i.e. it is polarization indifferent [17]. However, it is quite unlikely that these two directions ([001] and [100]) are the optical axes, knowing the real and imaginary principal axes of the complex dielectric tensor for the $x$ and $z$ components do not coincide.
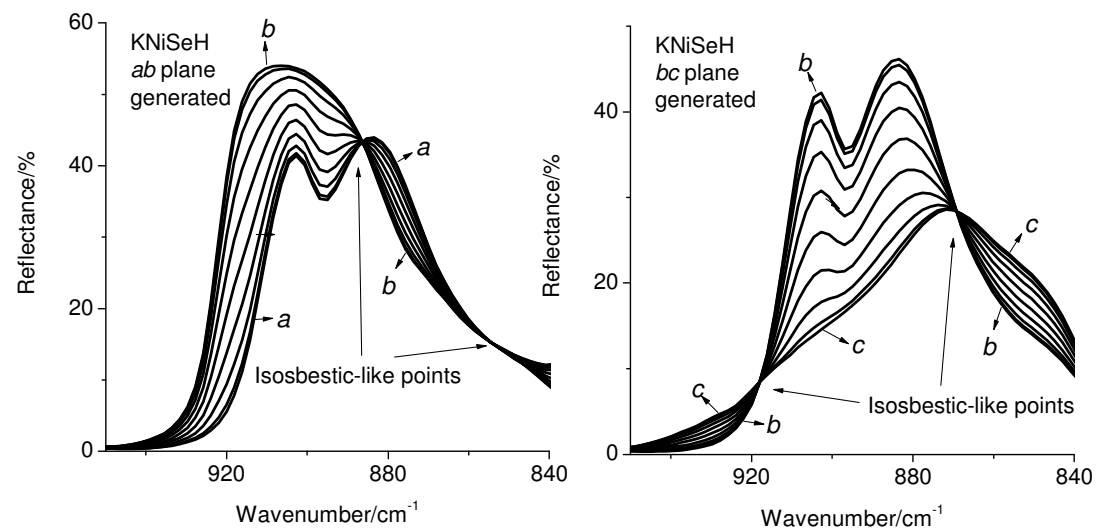

Fig. 6. Generated polarized IR reflectance spectra for $\mathrm{KNiSeH}$ single crystal planes $a b,(001)$ and $b c$, (100), using eq. (1). Recorded spectra with polarization along the $a$ and $b$ axes for (001), while spectra with polarization along the $b$ and $c$ axes for (100) were needed for the generation of the other spectra. ILP instead of ILR appears here. The spectra are practically identical to the originally measured in Figure 5. 
Even if the principal real and imaginary dielectric tensor's axes for some of the frequencies (modes) would be close, it would be difficult to explain why the ILP appeared for every overlapping band region, especially when the principal axes directions would be frequency dependent. It would also be inconsistent with the appearance of the ILR in every set of reflectance spectra, recorded from every plane parallel to the $b$ axis.
If the condition of perpendicularity was not satisfied, meaning that if stepwise polarized reflectance spectra were being recorded from a plane not parallel to the $b$ crystal axis, no ILR was expected to appear. This is demonstrated in Figure 7, where polarized spectra from the (111) crystal plane were recorded with a stepwise rotation of the $\mathrm{KNiSH}$ crystal around the [111] direction.

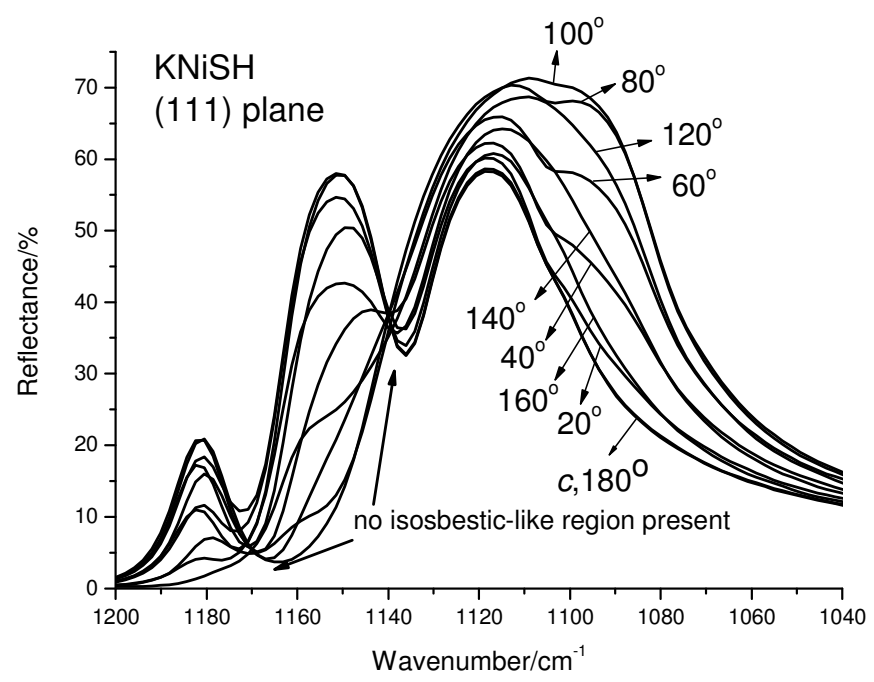

Fig. 7. Polarized reflectance spectra of KNiSH recorded from the (111) crystal plane. Spectra with polarizations ranging from $0^{\circ}$ to $180^{\circ}$ and a step of $20^{\circ}$ are shown. There are no ILRs present, and there are no pairs of matching spectra (as in Figure 5), except for $0^{\circ}$ (along the $c$ axis) and $180^{\circ}$, which are the same polarization direction. Polarization angles are also indicated, starting from the projection of the direction of the $c$ axis on the (111) plane.

As seen from Figure 7, the change in the polarization profiles of crystals were irregular in the sense that overlapping bands started to appear at some polarization angle, but did not reach their zero or near-zero reflectance values, and no distinct ILR was visible. Spectra in Figure 7 lack matching spectra for supplement pairs of polarization angles, as were seen in the experimental spectra in Figure 5. Although the corresponding spectra start from nearly a common point at the far right $\left(1040 \mathrm{~cm}^{-1}\right.$, cf. Figure 7), they quickly diverged.

The application of the second method to establishing the direction of the $b$ crystals axis (compared to the first method), did not require presumption of whether planes from which the spectra were recorded were symmetry equivalent or not. With respect to the cross-polarization method as will be shown, it has the advantage to be visually more suggestive due to the low reflectance of the crossed-polarization bands.

The cross-polarized IR reflectance method [21] uses polarization along the investigated direction, and the analyzer perpendicular to it. This experimental condition was supported by theory in Section 3, point 3. Namely, if the wave vector was perpendicular to the principal dielectric axis ( $y$ in this case) and the polarization of the wave was along this axis, the wave retained its polarization on normal reflection and refraction. However, if it was not the case, elliptic wave would result. On passing through an analyzer placed perpendicular to the polarizer, a portion of the radiation would pass to the detector if the reflected radiation was elliptically polarized. This radiation would be however very weak. On the other hand (with respect to previously discussed methods), the procedure is much easier, since recording only one spectrum is enough.

If the polarizer was oriented along the $b$ axis and analyzer perpendicular to it, near to $0 \%$ reflectance (depending on polarizer quality and experimental conditions) should result (cf. Figure 8). Although this percentage was comparable for both $\mathrm{KNiSH}$ and $\mathrm{KNiSeH},(0.8 \%$ and $0.2 \%$ respectively), the reflectance percentage along the other two crystal axes for both crystals were also low (7.5\% along the $a$ axis and $1 \%$ along the $c$ axis for $\mathrm{KNiSH}$, and $1.5 \%$ along $a$ and $1.2 \%$ along the $c$ axis for $\mathrm{KNiSeH}$ ). 

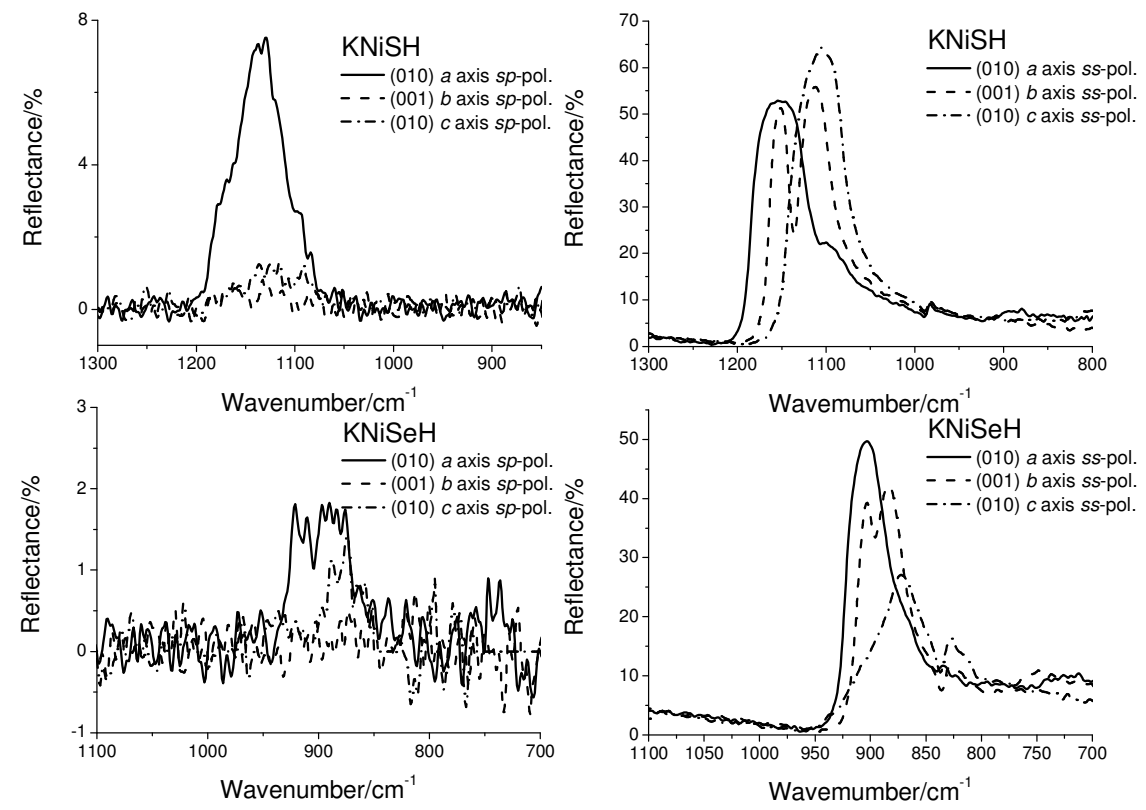

Fig. 8. Polarized reflectance spectra of $\mathrm{KNiSH}$ and $\mathrm{KNiSeH}$ (using polarizer and analyzer) in the stretching $\mathrm{SO}_{4}{ }^{2-}$ and $\mathrm{SeO}_{4}{ }^{2-}$ frequency regions, respectively. $s p$-cross-polarized spectra and $s s$-parallel-polarized spectra from the (010) plane were taken with polarization of the incidence beam along the $a$ and $c$ axis, while those from the (001) crystal face with polarization of the incidence beam along the $b$ axis.

The reflectance of the $s s$-polarized spectra (the polarizer and the analyzer were parallel to each other) yielded values for $\mathrm{KNiSH}$ of $53 \%$ along the $a$ axis, $56 \%$ along the $b$ axis and $64 \%$ along the $c$ axis, and for $\mathrm{KNiSeH}$ of $50 \%$ along the $a$ axis, $42 \%$ along the $b$ axis and $27 \%$ along the $c$ axis (cf. Figure 8). The reflectance $s s-$ and $s p$ spectra were recorded from the (001) plane for $b$ polarization of the polarizer, and from (010) plane for polarization directions along the $a$ and the $c$ axis for both crystals. Nevertheless, the percentage of non-compensation along the $a$ and $c$ axes for $\mathrm{KNiSH}$ and $\mathrm{KNiSeH}$, was characteristic only of the frequency regions of $v_{3}\left(\mathrm{SO}_{4}{ }^{2-}\right)$ and $v_{3}\left(\mathrm{SeO}_{4}{ }^{2-}\right)$ respectively, where the most prominent bands were present. The cross-polarized reflectance spectra in other frequency regions (like the $\mathrm{HOH}$ stretching region just above $3200 \mathrm{~cm}^{-1}$ ), showed little difference between $b, c$ or $a$ axes. These data indicated the IR cross-polarization reflection method should be used with caution when establishing the direction of the $b$ crystallographic axis in monoclinic crystals, because of the weak intensity of the noncompensations due to anisotropy along directions other than the $b$ axis.

\section{CONCLUSIONS}

Two methods were introduced that could be used to check or find the orientation of monoclinic single crystal's $b$ axis and the $a c$ crystal plane. The methods employed polarized IR reflectance spectroscopy for which a polarizer and a specular reflectance accessory were needed, something that is a standard equipment in a laboratory for IR spectroscopy. Both methods were based on the symmetry and dielectric properties of monoclinic single crystals. As model crystals, monoclinic single crystals of $\mathrm{KNiSH}$ and $\mathrm{KNiSeH}$ Tutton salts were used. Although both crystals belonged to the centrosymmetric monoclinic-prismatic crystal class $\left(C_{2 \mathrm{~h}}\right.$ factor group), the methods would also apply to crystals belonging to the other two non-centrosymmetric monoclinic crystal classes as well.

The first method takes advantage of the fact that the $y$ principal dielectric axis in monoclinic crystals is oriented along the $b$ crystal axis, so that IR $s$-polarized reflectance spectra recorded from any plane parallel to the $b$ axis, (and, with polarization direction along this axis) should be the same. However, it appears that same spectra were also obtained if recordings were taken from symmetry equivalent planes in the direction of polarization along the intersecting line of the planes. Thus, for both crystals, identical IR reflectance spectra resulted from (110) and (1 $\overline{1} 0)$ planes with polarization along the $c$ axis. For crystal classes with factor groups $C_{\mathrm{s}}$ or $C_{2}$, the equivalent planes would match each other by the symmetry element of reflection from a plane perpendicular to the $b$ axis or rotation about this axis, respectively. For uncovering the 
true $b$ axis direction, spectra from non-equivalent planes were needed. Thus, if $s$-polarized reflectance spectra recorded with the same direction of polarization from symmetry non-equivalent planes were identical, then the polarization direction was parallel to the $b$ crystal axis.

The second method was based on the rules for the appearance of an isosbestic-like point/region [26], a frequency (or frequency region) where all the polarized IR reflectance bands recorded from a particular plane had the same reflectance, which was represented as an intersecting point (or a relatively narrow region where intersecting points accumulated). As the $b$ crystal axis and the $a c$ crystal plane were perpendicular, planes formed by the $b$ axis and any direction in the $a c$ crystal plane should conform to the rule for the appearance of an isosbestic-like point/region. Thus, if isosbestic-like regions appeared for each group of polarized IR reflectance spectra recorded from different reflectance planes, the direction of plane intersection was the actual $b$ axis of the crystal. The two methods were compared with the crosspolarization method (already known to be applicable for crystal orientation), and cross-polarized spectra for the two crystals with polarizations along the crystal axes were recorded. The noncompensation due to anisotropy for the crosspolarized spectra along the $a$ or $c$ axis was no more than $7.5 \%$ and no less than $1 \%$ reflectance. The results of $0.8 \%$ to $0.2 \%$ non-compensation for the cross-polarized spectra, when the polarization is along the $b$ axis, were from polarizer imperfections. Moreover, no distinction could be made between the cross-polarized spectra for the polarizations along the $a, b$ or $c$ axis, when inspecting a region other than the frequency region where the most prominent bands (c.a. $50 \%$ reflectance) appear. Precautions must be taken when making a decision based on cross-polarization spectra.

Although each of the methods had advantages, they also had weaknesses. As a result, the orientation of the single crystal should be determined using at least two (if not all three methods) before a reaching the final decision.

Acknowledgements. I would like to thank the Alexander von Humboldt Foundation for the continuous financial support. I am also indebted to Prof. Vladimir M. Petruševski for his interest in this work.

\section{REFERENCES}

[1] V. Ivanovski, T. G. Mayerhöfer, J. Popp, Investigation of the peculiarities in the polarized reflectance spectra of some Tutton salt monoclinic single crystals using dispersion analysis Vib. Spectrosc., 44, 369-374 (2007).
[2] V. Ivanovski, T. G. Mayerhöfer, J. Popp, V. M. Petruševski, Polarized IR reflectance spectra of the monoclinic single crystal $\mathrm{K}_{2} \mathrm{Ni}\left(\mathrm{SO}_{4}\right)_{2} \cdot 6 \mathrm{H}_{2} \mathrm{O}$ : Dispersion analysis, dielectric and optical properties, Spectrochim. Acta A, 69, 629-641 (2008).

[3] V. Ivanovski, T. G. Mayerhöfer, J. Popp, Dispersion analysis of polarized IR reflectance spectra of Tutton salts: The $\mathrm{v}_{3}\left(\mathrm{SO}_{4}{ }^{2-}\right)$ frequency region, Vib. Spectrosc., 47, 91-98 (2008).

[4] V. Ivanovski, G. Ivanovski, Nearest-neighbourinteraction model in the coupled-optical-phonon-mode theory of the infrared dispersion in monoclinic crystals: Application to Tutton salt single crystal, Spectrochim. Acta A, 75, 1452-1461 (2010).

[5] M. Bukleski, V. Ivanovski, V. M. Petruševski, IR specular reflectance spectra of $\mathrm{KHSO}_{4}$ single crystal - Dispersion analysis, Vib. Spectrosc., 57, 15-22 (2011).

[6] Th. G. Mayerhöfer, H. H. Dunken, Single-crystal IR spectroscopic investigation on fresnoite, $\mathrm{Sr}$-fresnoite and Ge-fresnoite, Vib. Spectrosc., 25, 185-195 (2001).

[7] Th. G. Mayerhöfer, J. Popp, Employing spectra opolycrystalline materials for the verification of optical constants obtained from corresponding low-symmetry single crystals, Appl. Opt., 46, 327-334 (2007).

[8] J. Baran, Polarized infrared spectra of $\mathrm{KHSO}_{4}$ and $\mathrm{KDSO}_{4}$ single crystals, J. Mol. Struct., 172, 1-13 (1988).

[9] A. B. Kuz menko, E. A. Tishchenko, V. G. Orlov, Transverse optic modes in monoclinic $\alpha-\mathrm{Bi}_{2} \mathrm{O}_{3}$, J. Phys.: Condens. Matter, 8, 6199-6212 (1996).

[10] Th. G. Mayerhöfer, Modelling IR spectra of single-phase polycrystalline materials with random orientation in the large crystallites limit - extension to arbitrary crystal symmetry, J. Opt. A: Pure Appl. Opt., 4, 540-548 (2002).

[11] T. G. Mayerhöfer, Modelling IR-spectra of single-phase polycrystalline materials with random orientation - A unified approach, Vib. Spectrosc., 35, 67-76 (2004).

[12] T. G. Mayerhöfer, Z. Shen, R. Keding, J. L. Musfeldt, Optical isotropy in polycrystalline $\mathrm{Ba}_{2} \mathrm{TiSi}_{2} \mathrm{O}_{8}$ : Testing the limits of a well established concept, Phys. Rev. B, 71, 184116 (2005).

[13] M. E. Gunter, B. Twamley, A new method to determine the optical orientation of biaxial minerals: a mathematical approach, Can. Mineral., 39, 170-1711 (2001).

[14] C. Marín, E Diéguez, Orientation of Single Crystals by Back-Reflection Laue Pattern Simulation, World Scientific Publishing, Singapore, 1999.

[15] K. H. Lloyd, An X-ray goniometer for producing accurately oriented crystal faces, J. Appl. Cryst., 12, 127-128 (1979).

[16] J. C. Decius, R. M. Hexter, Molecular Vibrations in Crystals, McGraw-Hill, New York, 1977.

[17] M. Born, E. Wolf, Principles of Optics, $7^{\text {th }}$ (expanded) ed., Cambridge University Press, Cambridge, 1999.

[18] M. V. Belousov, V. F. Pavinich, Infrared reflection spectra of monoclinic crystals, Opt. Spectrosc., 45, 771-774 (1978).

[19] J. R. Aronson, A. G. Emslie, E. V. Miseo, E. M. Smith, P. F. Strong, Optical Constants of Monoclinic Anisotropic Crystals: Gypsum, Appl. Opt., 22, 4093-4098 (1983). 
[20] Th. G. Mayerhöfer, S. Weber, J. Popp, Simplified formulas for non-normal reflection from monoclinic crystals, Opt. Commun., 284, 719-723 (2011).

[21] Th. G. Mayerhöfer, J. Popp, Modelling IR spectra of polycrystalline materials in the large crystallites limit quantitative determination of orientation, J. Opt. A: Pure Appl. Opt., 8, 657-671 (2006).

[22] C. T. Johnston, S. F. Agnew, D. L. Bish, Polarized Single-Crystal Fourier-Transform Infrared Microscopy of Ouray Dickite and Keokuk Kaolinite, Clays Clay Miner., 38, 573-583 (1990).

[23] A. N. Winchell, H. Winchell, The Microscopical Characteristics of Artificial Inorganic Solid Substances: Optical Properties of Artificial Minerals, Academic Press, New York, 1964

[24] V. Ivanovski, V. M. Petruševski, M. K. Gunde, The IR reflectance spectra of the $v_{3}\left(\mathrm{SO}_{4}{ }^{2-}\right)$ and $v_{4}\left(\mathrm{SO}_{4}{ }^{2-}\right)$ band regions of some Tutton salts using polarized radiation: testing the model dielectric function, Spectrochim. Acta $A, \mathbf{6 1}, 67-76$ (2005).

[25] V. Ivanovski, V. M. Petruševski, Infrared reflectance spectra of some optically biaxial crystals: on the origin of isosbestic-like points in the polarized reflectance spectra, Spectrochim. Acta A, 61, 2057-2063 (2005).

[26] V. Ivanovski, T. G. Mayerhöfer, J. Popp, Isosbestic-like point in the polarized reflectance spectra of monoclinic crystals - A quantitative approach, Spectrochim. Acta A, 68, 632-638 (2007).

[27] T. Nowicka-Jankowska, Some properties of isosbestic points, J. Inorg. Nucl. Chem. 33, 2043-2050 (1971).
[28] M. D. Cohen, E. Fischer, Isosbestic points, J. Chem. Soc., 3044-3052 (1962).

[29] J. Brynestad, G. P. Smith, Isosbestic points and internally linear spectra generated by changes in solvent composition or temperature, J. Phys. Chem., 72, 296300 (1968).

[30] IUPAC. Compendium of Chemical Terminology, $2^{\text {nd }}$ ed. (the "Gold Book"). Compiled by A. D. McNaught and A. Wilkinson. Blackwell Scientific Publications, Oxford, 1997.

[31] P. G. Hodgeson, J. Whitnall, C. H. L. Kennard, F. H. Moore, Potassium Hexaaquanickel(II) sulphate, $\mathrm{H}_{12} \mathrm{~K}_{2} \mathrm{NiO}_{14} \mathrm{~S}_{2}$ (neutron), Cryst. Struct.Commun., 4, 713-716 (1975).

[32] H. Euler, B. Barbier, A. Meents, A. Kirfel, Crystal structure of Tutton's salts, $\mathrm{K}_{2}\left[\mathrm{M}^{\mathrm{II}}\left(\mathrm{H}_{2} \mathrm{O}\right)_{6}\right]\left(\mathrm{SeO}_{4}\right)_{2}, \mathrm{M}^{\mathrm{II}}=\mathrm{Co}, \mathrm{Ni}, \mathrm{Zn}$ and refinement of the crystal structure of potassium hexaaquamagnesium(II)selenate, $\mathrm{K}_{2}\left[\mathrm{Mg}\left(\mathrm{H}_{2} \mathrm{O}\right)_{6}\right]\left(\mathrm{SeO}_{4}\right)_{2}$, Z. Kristallogr. NCS, 224, 351-354 (2009).

[33] B. E. A. Saleh, M. C. Teich, Fundamentals of Photonics, John Wiley \& Sons, Inc., New York, 1991, p. 214.

[34] C. Punckt, F. S. Merkt, H. H. Rotermund, Simple reflection anisotropy microscopy set-up for CO oxidation studies, New J. Phys. 9, 213 (2007).

[35] V. Ivanovski, Th. G. Mayerhöfer, Vibrational spectra and dispersion analysis of $\mathrm{K}_{2} \mathrm{Ni}\left(\mathrm{SeO}_{4}\right)_{2} \cdot 6 \mathrm{H}_{2} \mathrm{O}$ Tutton salt single crystal doped with $\mathrm{K}_{2} \mathrm{Ni}\left(\mathrm{SO}_{4}\right)_{2} \cdot 6 \mathrm{H}_{2} \mathrm{O}$, Spectrochim. Acta A, 114, 553-562 (2013). 